\title{
A Near-Infrared Fluorescent Probe for Detection of Nitroxyl in Living Cells

\author{
LIU Ping ${ }^{1}$, HAN Xiao-Yue ${ }^{1,2}$, YU Fa-Biao ${ }^{1, *}$, CHEN Ling-Xin ${ }^{1, *}$ \\ ${ }^{1}$ Key Laboratory of Coastal Environmental Processes and Ecological Remediation, The Research Centre for Coastal Environmental \\ Engineering and Technology, Yantai Institute of Coastal Zone Research, Chinese Academy of Sciences, Yantai 264003, China \\ ${ }^{2}$ University of Chinese Academy of Sciences, Beijing 100049, China
}

\begin{abstract}
Nitroxyl (HNO), the one-electron reduced and protonated congener of nitric oxide (NO), has been demonstrated with excellent bio-pharmacological effects in cardiovascular disorder treatment, which is distinctive from that of NO. Despite its high reactivity, the accurate detection of HNO is a challenging issue. To resolve this problem, in this work, a near-infrared (NIR) metal-free fluorescent probe, ER-JN, was designed and synthesized for the detection of intracellular HNO concentration in simulated physiological conditions and living cells. The probe was consisted of two moieties, the $\mathrm{BF}_{2}$-chelated tetraarylazadipyrromethane fluorophore (aza-BODIPY) and the HNO recognition unit, diphenylphosphinobenzoyl group. The probe was purified by silica column chromatography eluting with $\mathrm{CH}_{2} \mathrm{Cl}_{2}$ to obtain the green solid product with a yield of $28 \%$. The as-prepared probe exhibited high sensitivity, good selectivity and low cytotoxicity, and was applied to fluorescent bio-imaging of $\mathrm{HNO}$ in simulated physiological conditions. When used in detection of $\mathrm{HNO}$, quantum yield of the probe increased from 0.01 to 0.35 . The linear range was $0-50 \mu \mathrm{M}$, with the detection limit of $0.03 \mu \mathrm{M}(S / N=3)$. With confocal laser scanning microscope imaging analysis, the probe could be used to detect HNO concentration in living cells. Furthermore, the results of flow cytometry confirmed that the probe could be employed for the qualitative and quantitative detection of intracellular HNO level. In this work, we found that probe ER-JN could not only detect HNO in aqueous solution and in living cells, but also target endoplasmic reticulum. We anticipate that ER-JN will provide experimental bases in studying physiological and pathological functions of $\mathrm{HNO}$ in cells, in vitro and in vivo.
\end{abstract}

Key Words: Fluorescent probe; Nitroxyl; Cell analysis; Near-infrared bioimaging

\section{Introduction}

Nitroxyl (HNO) is the one-electron reduced and protonated form of nitric oxide (NO), and displays distinct biological and pharmacological activities compared with NO. Due to its potential pharmacological activities, it has caused wide attention in recent years. HNO displays unique biological effects in the treatment of cardiovascular disorders such as angina and heart failure ${ }^{[1]}$. Angeli's salt (AS) (a HNO donor) is a potent vasodilator both in vitro and in vivo, and can elicit vasorelaxation in isolated large conduit, small resistance arteries and intact coronary arteries ${ }^{[2,3]}$. Moreover, HNO elicits distinct actions on myocardial contractile function that are not common to NO. Its cardiac effects are mediated by cardiac sarcoplasmic ryanodine receptors, which can effectively avoid the issue of nitroglycerin tolerance ${ }^{[4]}$, and may provide a potential treatment for cardiovascular diseases. Despite more and more evidences showing the pharmacological importance of $\mathrm{HNO}$, the understanding of endogenous HNO action mechanism is hampered by the lack of effective detection methods because HNO is unstable, and promptly dimerizes and dehydrates to nitrous oxide $\left(\mathrm{N}_{2} \mathrm{O}\right)^{[1,2,5]}$.

Many techniques are available for detecting $\mathrm{HNO}$, including electrochemistry, electron paramagnetic resonance 
(EPR), colorimetry and chemiluminescence method, etc ${ }^{[6,7]}$. Compared with these techniques, fluorescent probe based methods have the advantages of high resolution, high sensitivity, and noninvasive damage to biological specimens ${ }^{[8,9]}$. Nevertheless, few fluorescent probes for HNO detection were reported, and were mostly based on the reduction of $\mathrm{Cu}^{2+}{ }^{[10-12]}$. These fluorescent probes were susceptible to interferences from cellular reductants such as glutathione (GSH) and ascorbate. Moreover, the emission wavelengths of these reported probes were mainly located in UV-visible region. Because many organisms emit fluorescence under UV-visible light, the detection of biological samples using these probes might be interfered severely by the background autofluorescence. While the excitation/emission wavelengths of near-infrared (NIR) probes are located in $650-900 \mathrm{~nm}$, which can minimize photo damage and avoid noise from background autofluorescence ${ }^{[13,14]}$. Our group was committed to the development of probes for detecting RNS, RSS and $\operatorname{ROS}^{[13-19]}$. Recently, we reported two fluorescent probes (Lyso-JN and Cyto-JN) for detecting $\mathrm{HNO}^{[20,21]}$, which were used to test the change of cellular HNO level and applied to the fluorescent bio-imaging of HNO in mice. In this work, a near-infrared (NIR) metal-free fluorescent probe, ER-JN, was synthesized for the detection of intracellular HNO level in simulated physiological conditions and living cells. It was found that probe ER-JN could be used to detect HNO concentration in living cells with high sensitivity and low cytotoxicity.

\section{Experimental}

\subsection{Instruments and reagents}

All $\mathrm{pH}$ measurements were performed with a $\mathrm{pH}-3 \mathrm{C}$ digital pH meter (Shanghai Lei Ci Device Works, Shanghai, China). Fluorescence spectra were measured on FluoroMax-4 Spectrofluorometer with a Xenon lamp and 1.0-cm quartz cells. Absorption spectra were obtained on NANO Drop 2000c UV-visible spectrophotometer (Thermo Fisher
Scientific, USA). Fluorescence imaging of cells was performed on an Olympus Laser Scanning Confocal Microscope (FV1000, Olympus, Japan) at $60 \times$ magnifications Intracellular fluorescence detection was carried out on a flow cytometry (Aria, BD, USA) with excitation at $633 \mathrm{~nm}$ and emission in the range of 750-810 $\mathrm{nm}$. Mouse leukaemic monocyte macrophage cell line (RAW264.7) was obtained from the cell bank of the Shanghai Institute of Biochemistry and Cell Biology (Shanghai, China). Ultrapure water was used throughout. DMEM and trypsin were purchased from Gibco (Grand Island, USA). 3-(4,5-Dimethylthiazol-2-yl)-2,5diphenyltetrazolium bromide (MTT) was purchased from Sigma-Aldrich.

\subsection{Synthesis of probe ER-JN}

As shown in Fig.1, under argon atmosphere, a solution of Aza-BODIPY (52.9 mg, $0.1 \mathrm{mmol})$ in $\mathrm{CH}_{2} \mathrm{Cl}_{2}(50 \mathrm{~mL})$ was treated with 2-(diphenylphosphino) benzoic acid (61.2 mg, 0.2 mmol), 4-dimethylaminopyridine (DMAP, $24.4 \mathrm{mg}, 0.2 \mathrm{mmol}$ ) and 1-(3-(dimethylamino)propyl)-3-ethylcarbodiimide hydrochloride (EDC, $19.2 \mathrm{mg}, 0.1 \mathrm{mmol}$ ). The mixture was stirred at room temperature for $24 \mathrm{~h}$. The course of the reaction was monitored by thin layer chromatography (TLC). Then coarse product was neutralized with saturated $\mathrm{NaBr}$ solution, and partitioned with $\mathrm{CH}_{2} \mathrm{Cl}_{2}$ and $\mathrm{H}_{2} \mathrm{O}$. Then the solvent was evaporated under reduced pressure, and the obtained residue was purified by column chromatography. ER-JN was obtained as a green solid with a yield of $28 \%$. ${ }^{1} \mathrm{H}$ NMR (500 MHz, DMSO- $\left.D_{6}\right) \delta(\mathrm{ppm})$ : 8.31-8.01 (m, 1H), $7.53-7.40(\mathrm{~m}, 6 \mathrm{H}), 7.25-7.23(\mathrm{~m}, 23 \mathrm{H}), 7.16(\mathrm{~m}, 2 \mathrm{H})$, 6.98-6.94 (m, 2H), $4.05(\mathrm{~m}, 2 \mathrm{H}), 1.98(\mathrm{~m}, 2 \mathrm{H}), 1.26-0.98(\mathrm{~m}$, $37 \mathrm{H}) .{ }^{13} \mathrm{C}$ NMR (125 MHz, DMSO- $\left.D_{6}\right) \delta$ (ppm): 165.02, $162.82,157.01,152.12,137.63,137.54,134.31,134.14$, $133.97,133.63,131.84,131.66,131.00,129.96,129.77$, $129.63,129.52,125.39,129.31,129.26,129.21,129.16$, $122.40,121.27,116.72,60.22,30.01,21.02,14.55 .{ }^{31} \mathrm{P}$ NMR $\left(200 \mathrm{MHz}, \mathrm{CDCl}_{3}\right) \quad \delta \quad(\mathrm{ppm}):-4.05 . \quad \mathrm{LC}-\mathrm{MS} \quad\left(\mathrm{ESI}^{-}\right)$: $\mathrm{C}_{71} \mathrm{H}_{75} \mathrm{BF}_{2} \mathrm{~N}_{3} \mathrm{O}_{3} \mathrm{P}$ calcd. 1097. 56, found 1097. 57.
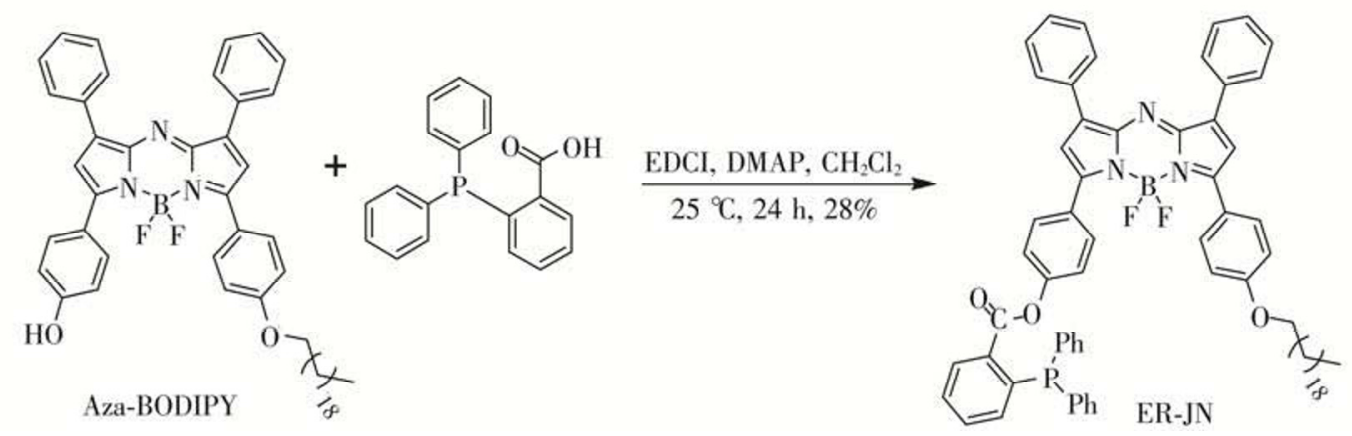

Fig.1 Synthetic route for probe ER-JN 


\subsection{Spectral analysis of probe ER-JN}

Tween $80(10 \%, 0.4 \mathrm{~mL})$ was added to a $10.0 \mathrm{~mL}$ color comparison tube and diluted to $10.0 \mathrm{~mL}$ with HEPES buffer (10 mM, pH 7.4), and then different concentrations of AS was added. Finally, probe ER-JN was added. The mixture was equilibrated for $20 \mathrm{~min}$, and then the absorption spectra and fluorescence spectra were measured.

\subsection{Cell culture}

RAW264.7 cells were grown in Dulbecco's modified Eagle's medium (DMEM) supplemented with $10 \%$ fetal bovine serum (FBS) in an atmosphere of $5 \% \mathrm{CO}_{2}$ and $95 \%$ air at $37{ }^{\circ} \mathrm{C}$. After the cells reached confluence, the cells were washed with PBS and detached with $0.25 \%$ trypsin solution.

\subsection{Cytotoxicity assays}

RAW264.7 cells were cultured in DMEM supplemented with $10 \% \mathrm{FBS}$ in an atmosphere of $5 \% \mathrm{CO}_{2}$ and $95 \%$ air at $37{ }^{\circ} \mathrm{C}$. The cells were inoculated into 96-well microplates (8000 per well) and incubated for $24 \mathrm{~h}$, and then treated with $0.1-100 \mu \mathrm{mol}$ of probe at $37{ }^{\circ} \mathrm{C}$ for $24 \mathrm{~h}$. After that, MTT solution $\left(5.0 \mathrm{mg} \mathrm{mL}^{-1}, 20 \mu \mathrm{L}\right)$ was added to each well and incubated for $4 \mathrm{~h}$. After the removal of MTT solution, DMSO (150 $\mu \mathrm{L} /$ well) was added to dissolve formazan crystals. The microplate was shaken for $10 \mathrm{~min}$ and the absorbance at 490 $\mathrm{nm}$ of each well was measured using a microplate reader (TECAN infinite M200pro).

\subsection{Confocal imaging}

RAW 264.7 cells were inoculated in cell culture petri dishes with $1 \mathrm{~mL}$ DMEM medium. Hoechst 33342, $\mathrm{DiOC}_{6}$ (3) (3,3'-Dihexyloxacarbocyanine iodide, $0.1 \mu \mathrm{M}$ ), probe ER-JN (DMEM, $0.1 \mu \mathrm{M})$ and HNO $(200 \mu \mathrm{M})$ were added sequentially and incubated for certain time periods, respectively. Prior to imaging, the cell medium was removed, and then cells were washed with DMEM thrice to remove excessive probe. Fluorescence imaging of cells were performed on an Olympus Laser Scanning Confocal Microscope (FV1000, Olympus) at $60 \times$ magnification.

\subsection{Flow cytometry analysis}

The cells were inoculated in 6 -well plate at $3.0 \times 10^{5}$ cells per well and incubated in an atmosphere of 5\% $\mathrm{CO}_{2}$ and $95 \%$ air at $37{ }^{\circ} \mathrm{C}$ for $24-48 \mathrm{~h}$. The cells were incubated with ER-JN $(5 \mu \mathrm{M})$ for $15 \mathrm{~min}$, and then treated with $200 \mu \mathrm{M}$ AS for 10 and $20 \mathrm{~min}$, respectively. After harvest, the cells were washed with DMEM twice and suspended in PBS and then analyzed by flow cytometry

\section{Results and discussion}

\subsection{Design of ER-JN}

In this work, a NIR fluorescent probe ER-JN was designed and synthesized for detection of HNO. The probe could target to endoplasmic reticulum (ER). As shown in Fig.2, ER-JN was composed of three moieties: the Aza-BODIPY fluorophore, the HNO recognition unit and the endoplasmic reticulum locating alkyl chain. The excitation/emission wavelengths of Aza-BODIPY fluorophore were in NIR region. Triphenylphosphonium as the recognition unit could react with $\mathrm{HNO}$, forming nitrogen-ylide intermediates, which might nucleophilically attack on the intramolecular suitably located ester to form a amide, resulting in the release of Aza-BODIPY and recovery of its fluorescence ${ }^{[20,21]}$. Liposoluble long-chain alkyl is a typical endoplasmic reticulum locator. The experimental results proved that ER-JN could offer good performances in detecting $\mathrm{HNO}$ concentration in endoplasmic reticulum of living cells.

\subsection{Spectroscopic properties of ER-JN}

We investigated the spectroscopic properties of probe ER-JN under simulated physiological conditions $(10 \mathrm{mM}$ HEPES buffer solution, $\mathrm{pH} 7.4,0.5 \%$ Tween 80 ). As shown in Fig. 3a, probe ER-JN $(5 \mu \mathrm{M})$ exhibited an absorption maximum at $675 \mathrm{~nm}, \varepsilon=5.2 \times 10^{4} \mathrm{M} \cdot \mathrm{cm}^{-1}$. Upon the addition

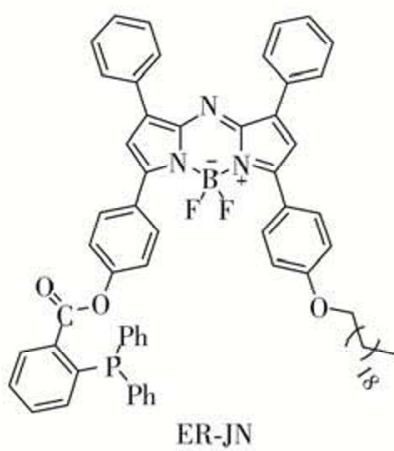

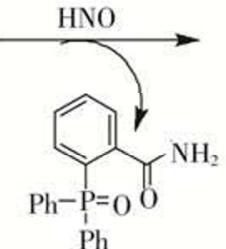

$\mathrm{Ph}$

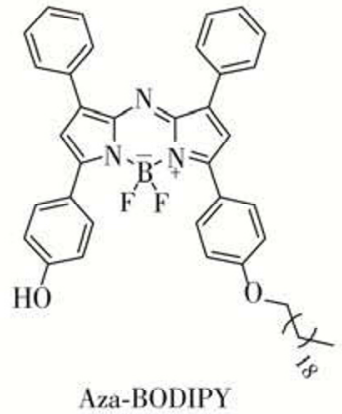

Aza-BODIPY

Fig.2 Proposed reaction mechanism for $\mathrm{HNO}$ detection 

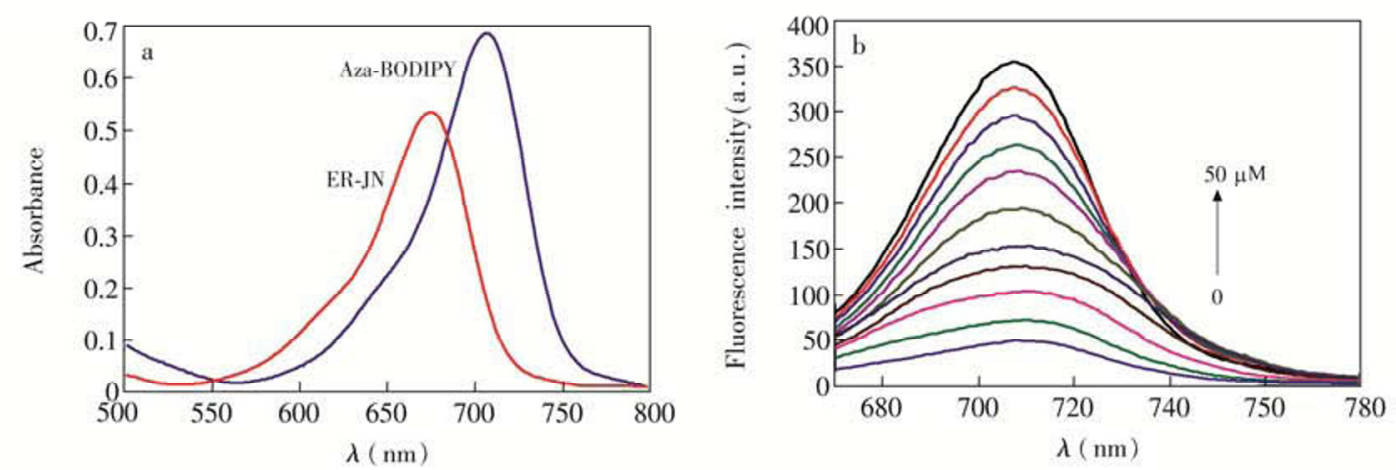

Fig.3 a. UV-vis absorption spectra of probe ER-JN $(10 \mu \mathrm{M})$ before and after the addition of $50 \mu \mathrm{M}$ HNO; b. Fluorescence spectra of ER-JN (10 $\mu \mathrm{M})$ upon the addition of $\mathrm{HNO}(0-50 \mu \mathrm{M})$ for $20 \mathrm{~min}$

of $50 \mu \mathrm{M} \mathrm{AS}$, the absorption peak at $675 \mathrm{~nm}$ disappeared whereas a new absorption peak centered at $707 \mathrm{~nm}, \varepsilon=6.9 \times$ $10^{4} \mathrm{M} \cdot \mathrm{cm}^{-1}$. indicating that the reaction between probe ER-JN and AS induced the break of ester bond and release of aza-BODIPY fluorophore. To evaluate the feasibility of ER-JN in the detection of HNO concentration under simulated physiological conditions, $690 \mathrm{~nm}$ was selected as the excitation wavelength. Fluorescence titration of ER-JN in the presence of AS at the HNO concentration range of $0-50 \mu \mathrm{M}$ in buffer solution was then performed. The corresponding fluorescence emission profiles, with a maximum emission at $710 \mathrm{~nm}$, increased with the HNO concentration, and the quantum yields of ER-JN increased from 0.01 to 0.35 . Moreover, there was a good linear relationship between fluorescent response of ER-JN and $\mathrm{HNO}$ concentration ranging from 0 to $50 \mu \mathrm{M}$ (Fig.4), and the calibration curve was $F_{700 \mathrm{~nm}}=6.3 C_{\mathrm{HNO}}(\mu \mathrm{M})+39.7(r=0.9981)$. The detection limit $(3 \sigma / \mathrm{k})$ was calculated to be $0.03 \mu \mathrm{M}$, indicating that ER-JN was highly sensitive to HNO. The result demonstrated that excitation and emission wavelength of ER-JN were both in the NIR region, and ER-JN would have good potential for application in cells and in vivo.

\subsection{Selectivity of ER-JN}

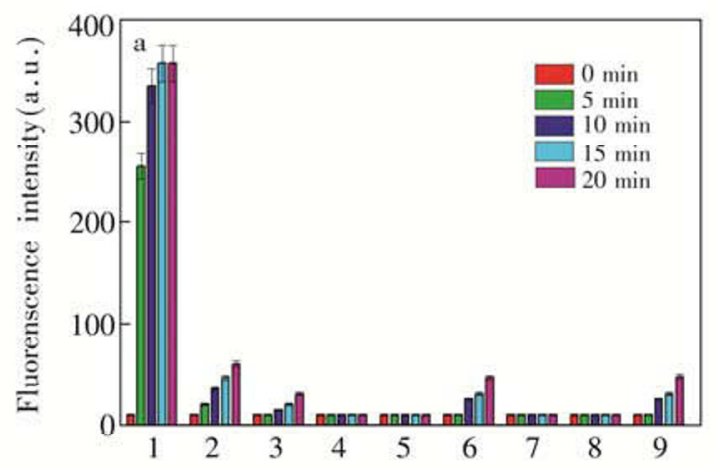

To assess the selectivity of ER-JN toward HNO, fluorescence signal of ER-JN was measured in solution upon the addition of physiologically relevant reactive oxygen species and reactive nitrogen species, and other common biologically relevant species. The result showed that the fluorescence responses to HNO far exceeded those of other biologically relevant species at the time points of $0,5,10,15$ and 20 min (Fig.5), indicating the good selectivity of probe ER-JN. In addition, the fluorescence intensity of ER-JN was hardly affected by glutathione (GSH), L-cysteine (Cys) as well as other biological reductants, reactive oxygen species and reactive nitrogen species. Some researchers suggested that

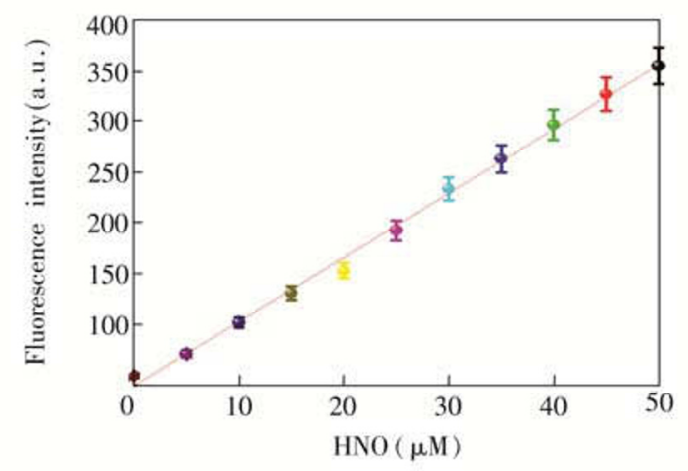

Fig.4 Linear relationship between the fluorescent intensity at 710 $\mathrm{nm}$ and AS concentration $(0-50 \mu \mathrm{M})$ in buffer solution

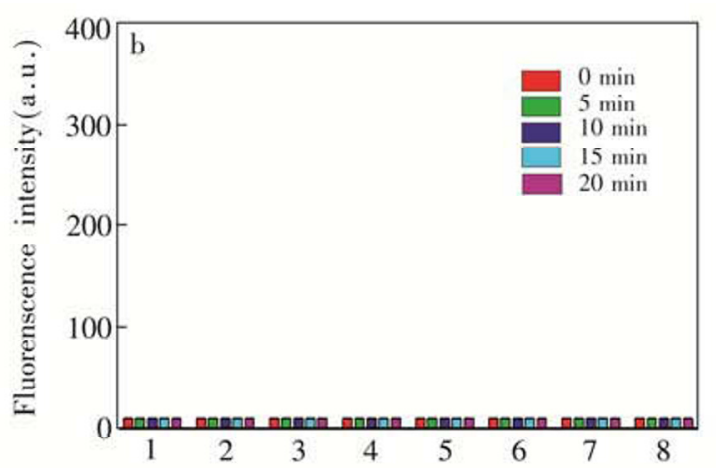

Fig.5 Fluorescence responses of $10 \mu \mathrm{M}$ ER-JN to testing species in HEPES buffer solution (a) 1, $50 \mu \mathrm{M} \mathrm{HNO} ; 2,20 \mu \mathrm{M}$ GSNO; 3, $200 \mu \mathrm{M} \mathrm{ONOO}^{-} ; 4,50 \mu \mathrm{M}$ NOC-5; 5, $500 \mu \mathrm{M} \mathrm{NO}_{2}^{-} ; 6,200 \mu \mathrm{M} \mathrm{H}_{2} \mathrm{O}_{2} ; 7,100 \mu \mathrm{M} \mathrm{O}_{2}^{-} ; 8,20 \mu \mathrm{M} \mathrm{MeLOOH} ; 9,200 \mu \mathrm{M} \mathrm{ClO}$. (b) 1, $50 \mu \mathrm{M}$ Cys; 2, $100 \mu \mathrm{M} \mathrm{GSH}$; 3, $500 \mu \mathrm{M} \mathrm{NaHS;} \mathrm{4,} 200 \mu \mathrm{M} \mathrm{Vc}$; , $200 \mu \mathrm{M} \mathrm{VE;} \mathrm{6,} 100 \mu \mathrm{M}$ Citrate; 7, $200 \mu \mathrm{M}$ tyrosine (Tyr); 8, $50 \mu \mathrm{M} \mathrm{HA}$ 


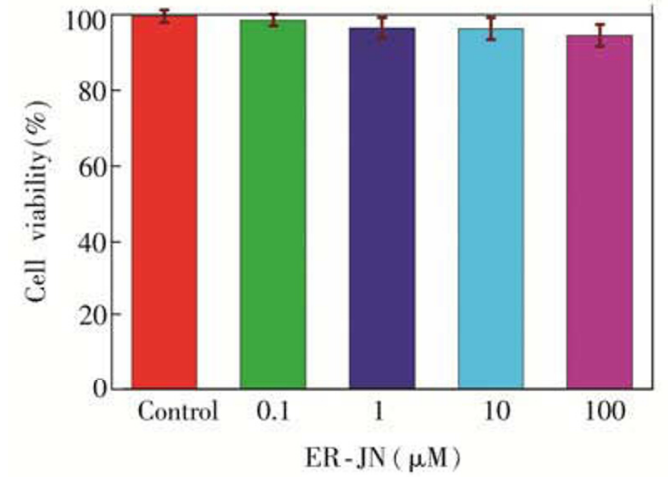

Fig.6 Cell viabilities of RAW264.7 cells after treated with $0.1-100$ $\mu \mathrm{M}$ of ER-JN for $24 \mathrm{~h}$. Data were expressed as the means \pm $\mathrm{SD}$ of data obtained from triplicate experiment

GSNO could form amide in a fashion similar to HNO. As shown in Fig.5, GSNO could elicit response and cause the comparatively limited fluorescence change in $20 \mathrm{~min}$. However, the change of fluorescence caused by GSNO was comparatively smaller than that of HNO. The above experiments results indicated that ER-JN had better selectivity to $\mathrm{HNO}$ over GSNO. At the same time, $\mathrm{NO}_{2}^{-}$, another decomposition product of AS, showed no obvious influence on ER-JN fluorescence. Therefore, in competition experiments, ER-JN could recognize HNO without disturbance of other biologically relevant species, further proving that the probe ER-JN possessed excellent selectivity towards HNO.

\subsection{Cytotoxic effect of ER-JN}
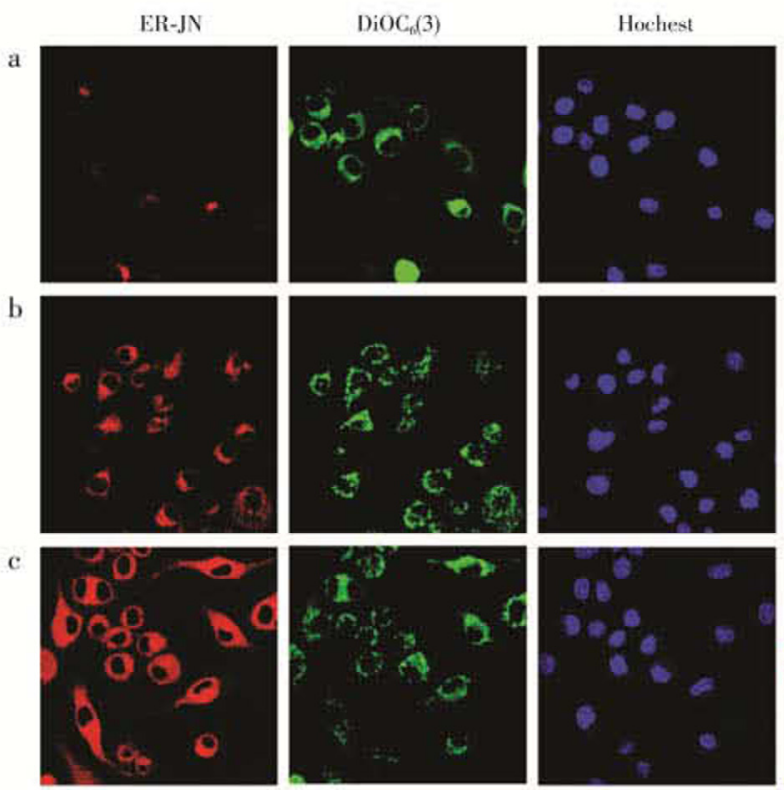

Low cytotoxicity is a key criterion for the physiological application of fluorescent probe in cells. The cytotoxicity of ER-JN was evaluated by MTT assay using RAW 264.7 cells. As illustrated in Fig.6, the cell viabilities were over 90\% after incubation with $0.1-100 \mu \mathrm{M}$ ER-JN for $24 \mathrm{~h}$. The results demonstrated that the probe ER-JN had good biocompatibility, and could be used in the detection of HNO in cells.

\subsection{Bioimaging of HNO in cells}

On the basis of the high sensitivity and selectivity features of ER-JN for the detection of $\mathrm{HNO}$ in solution, its applicability in imaging HNO in living cells was investigated utilizing laser scanning confocal microscopy. After incubated with $1 \mu \mathrm{M}$ ER-JN for $15 \mathrm{~min}$, RAW 264.7 cells displayed faint fluorescence (Fig.7a). Next, $200 \mu \mathrm{M}$ AS was added to the system and left for $10 \mathrm{~min}$, and a strong intracellular fluorescence was observed (Fig.7d). With the passage of time, the cells were emited stronger fluorescence (Fig.7g). The results suggested that ER-JN was suitable for test the change of cellular HNO concentration. We introduced a endoplasmic reticulum targeted dye $\mathrm{DiOC}_{6}$ (3) (3,3'-dihexyloxacarbocyanine iodide) and a nucleus fluorescence marker Hochest 33342 to discern the cellular location of ER-JN in RAW264.7 cells. As shown in Fig.7 (c, f and i), the fluorescence of ER-JN exhibited a consistent overlap with $\mathrm{DiOC}_{6}$ (3), while showed hardly any overlap with the nucleus dye Hochest 33342. The results verified that ER-JN, with subcellular localization in endoplasmic reticulum, could be used for fluorescence detection of HNO in living cells.
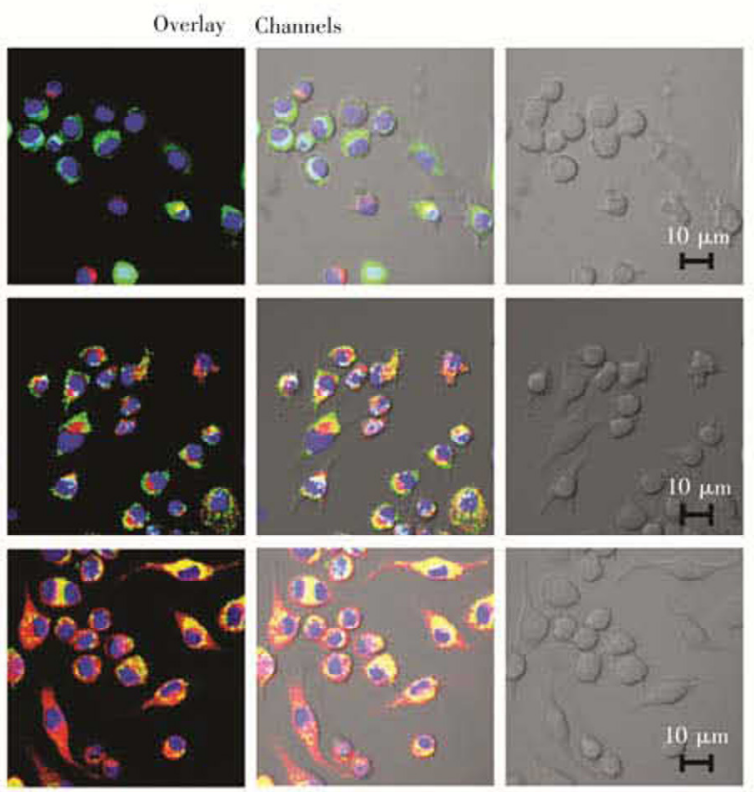

Fig.7 Confocal fluorescence images of HNO in RAW 264.7 cells treated with ER-JN

(a) Cells loaded with $1 \mu \mathrm{M}$ probe for $15 \mathrm{~min}$. (b) and (c) Cells treated with $200 \mu \mathrm{M}$ HNO for 10 and 20 min, respectively; In each group: ER-JN bioimage from red channel. $\mathrm{DiOC}_{6}$ (3) bioimage from green channel. Hochest 33342 bioimage from blue channel. Overlay of red channel, green channel and blue channel, and overlay of red channel, green channel, blue channel and bright field. Red channel: $\lambda_{\mathrm{ex}}=690 \mathrm{~nm}, \lambda_{\mathrm{em}}=700-800 \mathrm{~nm}$; Green channel $\lambda_{\mathrm{ex}}=488 \mathrm{~nm}, \lambda_{\mathrm{em}}=560-600 \mathrm{~nm}$; Blue channel: $\lambda_{\mathrm{ex}}=405 \mathrm{~nm}, \lambda_{\mathrm{em}}=420-480 \mathrm{~nm}$ 

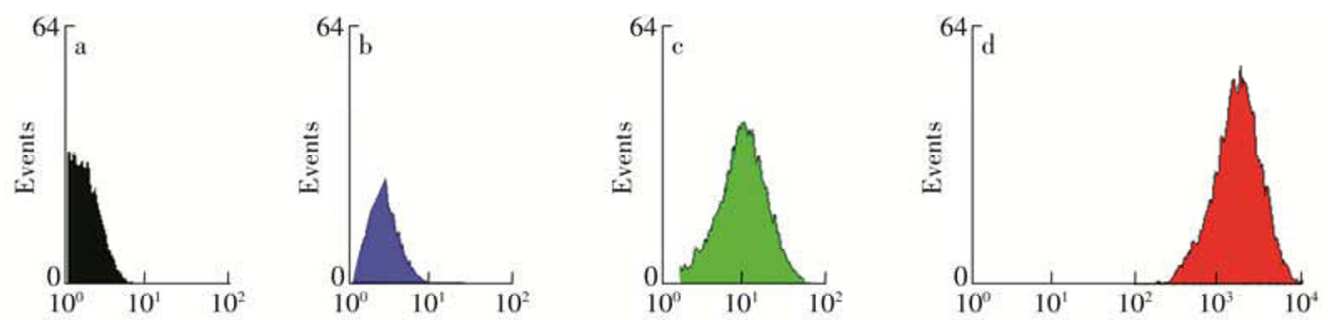

Fig.8 Representative data of flow-cytometric analysis

(a) Control; (b) The cells were incubated with $1 \mu \mathrm{M}$ ER-JN for $15 \mathrm{~min}$, then washed with DMEM three times to remove the overdose probe; (c) The cells were treated as described in (b), then incubated with $200 \mu \mathrm{M} \mathrm{HNO}$ for $10 \mathrm{~min}$; (d) The cells were treated as described in c), then exposed to another dosages of $200 \mu \mathrm{M}$ HNO for an additional $10 \mathrm{~min}$

\subsection{Flow cytometric analysis}

Laser scanning confocal microscope is suitable for analysis of a relatively small numbers of cells only in visual fields, while flow cytometry (FCM) can detect millions of cells sensitively and rapidly, and provide more statistically reliable results. Therefore, flow cytometric analysis was also employed to analyze the fluorescence changes in living cells caused by HNO. As shown in Fig.8, the $\mathrm{X}$ axis represents fluorescent intensity and the $\mathrm{Y}$ axis represents cells counts. The cells were divided into four groups: group a was a blank group set for control; in group $\mathbf{b}$, the cells were incubated with ER-JN for 15 min and then washed with DMEM; in group c, the cells were treated as described in group $\mathbf{b}$, and then incubated with $200 \mu \mathrm{M}$ HNO for another $10 \mathrm{~min}$; in group d, the cells were treated as described in group c, and then exposed to another $200 \mu \mathrm{M}$ for $10 \mathrm{~min}$. It was obvious that cells in group a and $\mathbf{b}$ had faint fluorescence, and the cells in group $\mathbf{c}$ with the addition of $\mathrm{HNO}$ emitted relatively stronger fluorescence, whereas more significant increase of fluorescence in group $\mathbf{d}$ with the addition of double dosage of HNO was obtained. The FCM results were in consistent with the fluorescence imaging results shown in Fig.7, indicating that the synthesized probe ER-JN could be used to detect the changes of HNO concentration in living cells qualitatively and quantitatively.

\section{Conclusions}

In summary, a novel NIR fluorescent probe ER-JN was synthesized in this work, with aza-BODIPY as fluorophore and triphenylphosphine as recognition unit, for detection of changes of HNO concentration in living cells. The ER-JN probe exhibited remarkable "turn-on" fluorescence response towards HNO and showed high selectivity, good sensitivity and low cytotoxicity. Moreover, the probe could locate in endoplasmic reticulum and be used to detect the changes of HNO concentrations in living cells. These results demonstrated that probe ER-JN had great significance and practical value for the research of biological and pathological functions of HNO in subcellular fractions, living cells, organs and even in living organism.

\section{References}

[1] Irvine J C, Ritchie R H, Favaloro J L, Andrews K L, Widdop R E, Kemp-Harper B K. Trends Pharmacol. Sci., 2008, 29(12): 601-608

[2] Paolocci N, Jackson M I, Lopez B E, Miranda K, Tocchetti C G, Wink D A, Hobbs A J, Fukuto J M. Pharmacol. Ther., 2007, 113(2): 442-458

[3] Favaloro J L, Kemp-Harper B K. Cardiovasc. Res., 2007, 73(3): 587-596

[4] Paolocci N, Saavedra W F, Miranda K M, Martignani C, Isoda T, Hare J M, Espey M G, Fukuto J M, Feelisch M, and Wink D A. Proc. Natl. Acad. Sci. USA., 2001, 98(18): 10463-10468

[5] Dutton A S, Fukuto J M, Houk K. J. Am. Chem. Soc., 2004, 126(12): 3795-3800

[6] Malinski T, Taha Z, Nature, 1992, 358(6388): 676-678

[7] Nagano T, Yoshimura T. Chem. Rev., 2002, 102(4): $1235-1270$

[8] Li X, Gao X, Shi W, Ma H. Chem. Rev., 2014, 114(1): 590-596

[9] Wang R, Yu C, Yu F, Chen L. TrAC. Trends Anal. Chem., 2010, 29: 1004-1013

[10] Wrobel A T, Johnstone T C, Deliz Liang A, Lippard S J , Rivera-Fuentes P. J. Am. Chem. Soc., 2014, 136(12): 4697-4705

[11] McQuade L E, Lippard S J. Curr. Opin. Chem. Biol., 2010, 14(1): 43-49

[12] Zhou Y, Liu K, Li J, Fang Y, Zhao T, Yao C. Org. Lett., 2011, 13(6): 1290-1293

[13] Wang R, Yu F, Chen L, Chen H, Wang L, Zhang W. Chem. Commun., 2012, 48(96): 11757-11759

[14] Wang R,Yu F, Liu P, Chen L. Chem. Commun., 2012, 48(43): 5310-5312

[15] Jing X, Yu F, Chen L. Process in Chemistry, 2014, 26(5), 866-878

[16] Gao M, Yu F, Chen L. Process in Chemistry, 2014, 26(6), 
1065-1078

[17] Wang R, Chen L, Liu P, Zhang Q, Wang Y Q. Chem. Eur. J., 2012, 18(36): 11343-11349

[18] Gao M, Yu F, Chen H, Chen L. Anal. Chem., 2015, 87(7): $3631-3638$
[19] Gao M, Wang R, Yu F, You J, Chen L. Analyst, 2015, 140(11): 3766-3772

[20] Jing X, Yu F, Chen L. Chem. Commolun., 2014, 50: 14253

[21] Liu P, Jing X, Yu F, Lv C, Chen L. Analyst, 2015, 140(13), $4576-4583$ 